\title{
RADIATION-INDUCED LUNG INJURY IN VIVO: EXPRESSION OF TRANSFORMING GROWTH FACTOR-BETA PRECEDES FIBROSIS
}

\author{
EUNHEE S. YI, ${ }^{1}$ ADRIANA BEDOYA, ${ }^{1}$ HYESUN LEE, ${ }^{1}$ \\ ELAINE CHIN, ${ }^{2}$ WILLIAM SAUNDERS, ${ }^{2}$ \\ SEONG-JIN KIM, ${ }^{3}$ DAVID DANIELPOUR, ${ }^{3}$ \\ DANIEL G. REMICK, ${ }^{4}$ SONGMEI YIN, ${ }^{\prime}$ \\ and THOMAS R. ULICH ${ }^{1}$ \\ Department of 'Pathology and ${ }^{2}$ Radiation Oncology \\ University of California at San Diego School of Medicine \\ San Diego, California \\ ${ }^{3}$ Laboratory of Chemoprevention \\ National Cancer Institute \\ Bethesda, Maryland \\ ${ }^{4}$ Department of Pathology \\ University of Michigan School of Medicine \\ Ann Arbor, Michigan
}

\begin{abstract}
Cytokine release from irradiated cells has been postulated to start soon after irradiation preceding detectable clinical and pathological manifestation of lung injury. The expression of transforming growth factor beta (TGF $\beta$ ), a fibrogenic and radiation-inducible cytokine, was studied from $1-16$ weeks after the 15 and 30 Gray (Gy) of thoracic irradiation to rats. Thoracic irradiation caused an increase in TGF $\beta$ protein in bronchoalveolar lavage (BAL) fluid peaking at 3-6 weeks as compared to sham-irradiated control rats. Steady state TGF $\beta$ mRNA expression as shown by whole lung northern blot assay paralleled the TGF $\beta$ protein expression in BAL fluid. The peak of TGF $\beta$ protein increase in BAL fluid between 3 and 6 weeks coincided with the initial influx of inflammatory cells in BAL fluid, but preceded histologically discernable pulmonary fibrosis that was not apparent until 8-10 weeks after irradiation. In conclusion, TGF $\beta$ and mRNA and protein upregulation preceded the radiation-induced pulmonary fibrosis, suggesting a pathogenetic role in the development of radiation fibrosis.
\end{abstract}

\section{INTRODUCTION}

Ionizing radiation produces free radicals that cause oxidative injury to cell organelles in susceptible cells (1). The outcome of radiation at an organ level, how- 
ever, depends not only on the individual cell response but also on the autocrine, paracrine, and endocrine interaction of the various types of radiated cells via the release of cytokines and growth factors $(2,3)$. Ionizing radiation to the normal lung tissue causes radiation pneumonitis and fibrosis that typically occur after 1-3 months of a latent period during which clinical pathological manifestations are not detectable (1). The importance of molecular events during this clinically silent latent period after thoracic irradiation has been only recently appreciated (4). Release of cytokines and growth factors during the latent period are postulated to be crucial in the development of the later lung injury (4). However, the kinetics of the in vivo expression of cytokines in the latent phase or in the later stage accompanying detectable lung injury is still largely unknown. A better understanding of cytokine interactions in radiation injury may prove clinically useful as suggested by a study demonstrating the beneficial effect of interferon gamma treatment in a rat radiation pneumonitis model (5).

TGF $\beta$ exerts multiple effects on mesenchymal cells including enhancement of the expression of both fibronectin and collagen by fibroblasts. TGF $\beta$ has been reported to be inducible and activated by radiation of the liver and mammary gland $(2,6)$. Changes in plasma TGF $\beta$ levels during radiotherapy have been reported as a predictor of the risk of developing radiation pneumonitis in humans (7). Early alterations in TGF $\beta$ gene expression have been reported as an indicator for later fibrosis in a mouse lung radiation model (8).

The purpose of the present study was to investigate the expression of TGF $\beta$ in the evolution of radiation-induced lung injury in vivo. The kinetics of inflammatory cell exudation in BAL fluid and histologic changes were also studied and correlated with the kinetics of TGF $\beta$ expression.

\section{METHODS}

General Experimental Design. Rats were divided into three groups receiving thoracic irradiation at doses of: 1) $15 \mathrm{~Gy}$ in both lungs, 2) $30 \mathrm{~Gy}$ in right lung only or in both lungs, and 3) sham irradiation. At various time points ranging from 1 to 16 weeks after the $15 \mathrm{~Gy}, 30 \mathrm{~Gy}$ irradiation ( $n=3$, each time point) or sham-irradiation ( $n=2$, each time point), rats were sacrificed for BAL to enumerate inflammatory cell counts and to measure cytokine levels. All lungs were histologically examined after the BAL procedure. Whole lung northern blot assay was performed with a naive rat and rats $(n=4)$ receiving $30 \mathrm{~Gy}$ of radiation in both lungs to determine TGF $\beta$ mRNA expression.

Thoracic Irradiation. Male Sprague-Dawley rats weighting approximately 225 grams were anesthesized by intraperitoneal injection of sodium pentobarbital at a dose of $1 \mathrm{mg}$ per $\mathrm{kg}$ of body weight. The rats were treated with a single anterior field utilized either a 6 or $10 \mathrm{MV}$ linear accelerator photon beam. A dose of 15 or $30 \mathrm{~Gy}$ was delivered at a rate of $1.5 \mathrm{~Gy} /$ minute to the level of midplane (approximately $1.5 \mathrm{~cm}$ ). All rats in $15 \mathrm{~Gy}$ dose group received whole lung irradiation, and all rats in 30 Gy group except 4 rats for molecular biology received right lung 
irradiation only. A sufficient thickness of tissue equivalent material was added in order to provide electronic equilibrium, thus the total dose gradient was approximately $\pm 6 \%$ for the $10 \mathrm{MV}$ photon energy and $\pm 7 \%$ for the $6 \mathrm{MV}$. The rats were secured supine with a $4 \mathrm{~cm} \times 4 \mathrm{~cm}$ radiation field encompassing both lungs or with a $2 \mathrm{~cm} \times 4 \mathrm{~cm}$ radiation field including the right lung only. The animals were visually monitored for movement throughout the treatment period. Sham irradiated rats received the same anesthesia and manipulation but were not exposed to radiation. After radiation, all rats were given prophylactic tetracyclin in chlorinated drinking water $\left(500 \mathrm{mg} / 100 \mathrm{~m}^{\top}\right.$ and had free access to Purina Rat Chow (Ralston Purina Company, St. Louis, Missouri).

Bronchoalveolar Lavage. At various time points ranging from 1-16 weeks after radiation treatment, rats were sacrificed and BAL was performed to enumerate the absolute numbers of inflammatory cells in the intraalveolar exudate as previously described with minor modifications (9). In the rats receiving $30 \mathrm{~Gy}$ of irradiation in the right hemithorax, separate BAL was performed in the right and left lungs by clamping the main bronchi alternately. Each lung was lavaged with 7 $\mathrm{ml}$ of Hank's essential medium, instead of $14 \mathrm{ml}$ for the whole lung BAL, with recovery of approximately $5 \mathrm{ml}$. The absolute numbers of total nucleated cells in BAL fluid were counted with an automated cell counter (Sysmax, Irvine, California). Differential counts of leukocyte subsets were determined by counting 200 nucleated blood cells after modified Wright-Giemsa staining (DiffQuik; Scientific Products, McGaw Park, Illinois) on cytospin preparation. The absolute numbers of each leukocyte subset were calculated by multiplying the total and differential and were expressed as the mean \pm one-standard deviation of the mean. The probability value was determined by the $t$-test (Systat, Evanston, Illinois).

Cytokine Assay. Cell free BAL supernatants were used to measure protein levels of TGF $\beta$. TGF $\beta$ protein level was measured by sandwich enzyme-linked immunoabsorbent assay (ELISA) using TGF $\beta 1$-specific turkey and rabbit polyclonal antibodies as previously described (10). Data obtained by serial dilution of BAL specimens ( 3 dilutions in triplicate) was presented as the mean \pm one standard deviation of the mean per $\mathrm{ml}$ of BAL. The probability value was determined by the $t$-test (Systat, Evantson, Illinois).

Northern Blot Assay. The mRNA expression of TGF $\beta$ was examined in rats at time 0 (naive rat) and at 1,2,3, and 4 weeks after 30 Gy irradiation to the whole lung field. While the heart was still beating after deep anesthesia with excessive ether, the lungs were removed, immediately frozen in liquid nitrogen, and stored in $-70^{\circ} \mathrm{C}$ freezer. At the time of the assay, lungs were thawed and homogenized for 30 seconds with a tissue homogenizer. Total cellular RNA was extracted by guanidine isothiocyanate/cesium chloride method (1). The yield and purity of RNA was quantitated by measuring the ratio of the absorbences at 260 and $280 \mathrm{~nm}$. Successful isolation of undegraded RNA was monitored by mini-gel electrophoresis in the presence of ethidium bromide and examination of the sharpness of the $28 \mathrm{~S}$ and $18 \mathrm{~S}$ ribosomal RNA bands under ultraviolet light. Standard northern blotting was performed by electrophoretic separation of total RNA ( $10 \mu \mathrm{g} / \mathrm{lane})$ on a $1.0 \%$ agarose/1.1M formaldehyde gel followed by blotting of the RNA onto a nylon membrane (DuralonUV $^{\mathrm{Tm}}$; Stratagene, La Jolla, California). RNA blots were hybridized with probes corresponding to the rat TGF $\beta 1$ cDNA cloned as previously described (12). After hybridization, the blots were washed at $65^{\circ} \mathrm{C}$ for 15 minutes, twice with $2 \mathrm{XSSC}$ and $0.1 \%$ SDS and twice with $0.2 \mathrm{X} \mathrm{SSC}$ and $0.1 \%$ SDS.

Histology and Immunohistochemistry. After BAL procedure all lungs were processed for histologic evaluation. A midsagittal section of the right and left lung encompassing the largest surface area was taken. Formalin-fixed paraffin embedded lung sections were examined to determine the extent of pneumonitis and fibrosis with hematoxylin eosin and masson-trichrome stainings. Formalin-fixed paraffin-embedded lung tissue was used for immunohistochemical localization of TGF $\beta$ and surfactant apoprotein in selected blocks. Antibodies to TGF $\beta$ detecting extracellular secreted form of TGF $\beta 1$ (gift of Dr. K. Flanders at NCI; $1: 1,000$ dilution) and surfactant apoprotein SP-B (gift of Dr. J. Whisett at Children's Hospital, Cincinnati, Ohio; $1: 100$ dilution) were used 
as primary antibodies. Standard avidin-biotin-complex (ABC) immunohistochemical staining was performed with biotinylated secondary antibody and 3'3 diaminobenzidine tetrachloride (Sigma, St. Louis, Missouri) as chromogen (13).

\section{RESULTS}

TGF $\beta$ immunoassay of the BAL fluids showed an increase in TGF $\beta$ between 3 and 8 weeks, peaking at 3-6 weeks, as compared to the sham-irradiated control rats $(p=0.03$, pooled values at 3-8 weeks after 30 Gy irradiation) (Figure 1$)$. Constitutive TGF $\beta$ gene expression was detected in naive rat lungs at time 0 (Figure 2). The upregulation of steady-state TGF $\beta$ mRNA expression was dis-

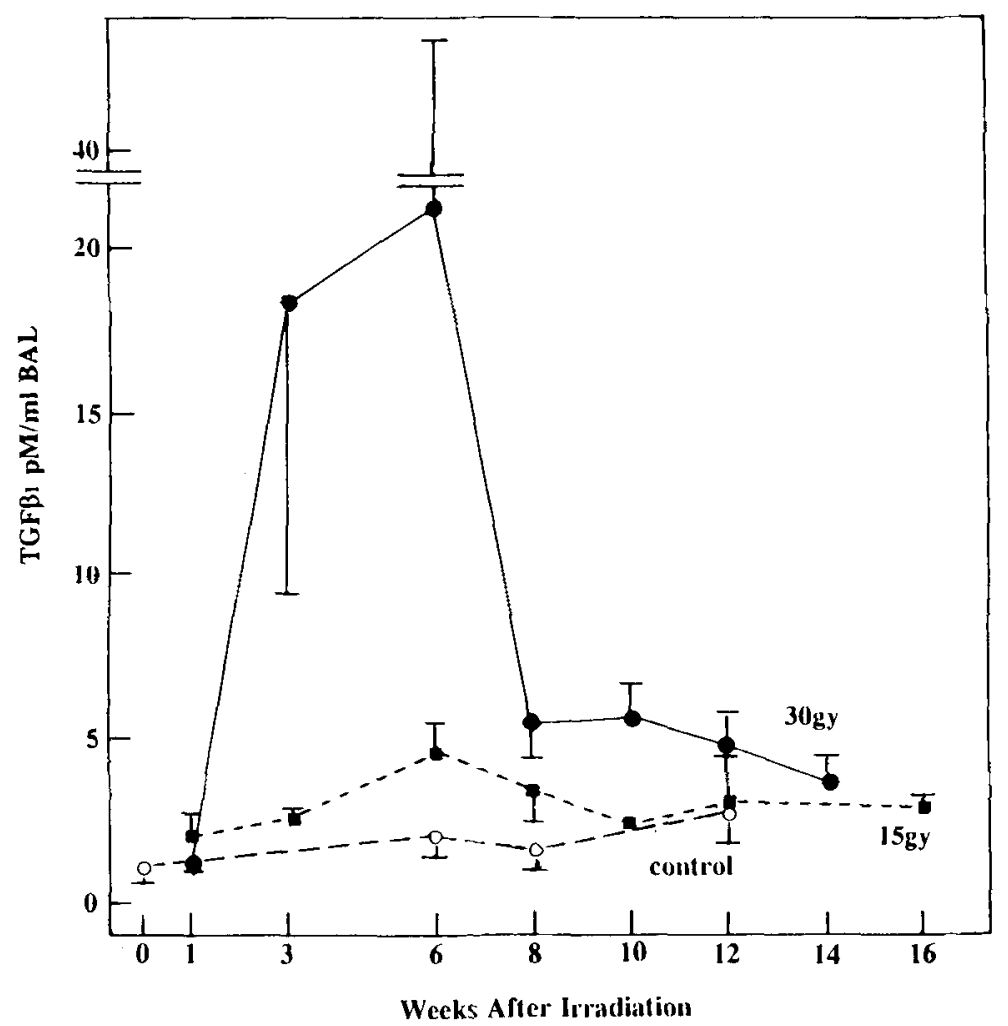

Fig. 1. TGF $\beta$ protein increase in BAL fluid was radiation dose-dependent and peaked at 3 to 6 weeks after thoracic irradiation as shown by sandwich enzyme-linked immunoabsorbant assay. 


\section{TGFß। mRNA}

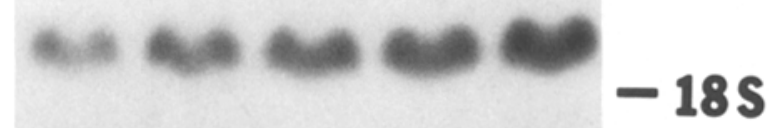

r RNA

Fig. 2. Whole lung northern blot assay showed steady-state TGF $\beta$ mRNA upregulation as early as 1 week after $30 \mathrm{~Gy}$ of thoracic irradiation. TGF $\beta$ mRNA expression gradually increased till 4 weeks as compared to the constitutive expression at time 0 before radiation.

cernable as early as 1 week and remained increased until 4 weeks after the 30 Gy radiation as shown by whole lung northern blot assay (Figure 2).

After 30 Gy irradiation to the right hemithorax, inflammatory cell counts in BAL fluid from the right lung were compared against the cell counts from the left lung that was not exposed to radiation (Figure 3). The greatest increase in PMN counts was detected mostly between 3 and 10 weeks after the radiation as compared to the unradiated left lungs ( $p<0.0001$, pooled values at 3 to 10 weeks). Elevated lymphocyte counts were also observed from 3 to 10 weeks after radiation as compared to the left lungs ( $p=0.001$, pooled values at 3 to 10 weeks). There was no significant difference in macrophage/monocyte counts throughout the course except for a slight early decline at 1 week (data not shown). The BAL cell counts in rats with 15 Gy radiation showed similar kinetics of intraalveolar PMN and lymphocyte exudation, but lesser in extent (data not shown). Sham-irradiated rats did not show any increase in the BAL inflammatory cell counts over time (data not shown).

Histologically, the radiated right lung showed no remarkable changes until 



Fig. 3. Neutrophil and lymphocyte counts in BAL fluids of the right lungs were increased mostly between 3 to 10 weeks after 30 Gy irradiation as compared to the non-radiated left lungs of the same rats.

3 weeks after $30 \mathrm{~Gy}$ irradiation at which time perivascular edema was first noticeable. Intraalveolar edema and inflammatory cell infiltration developed after 4 weeks, became most prominent at 6 to 8 weeks (Figure 4), and subsided at later time points. Active fibroblastic proliferation and trichrome-positive colla- 


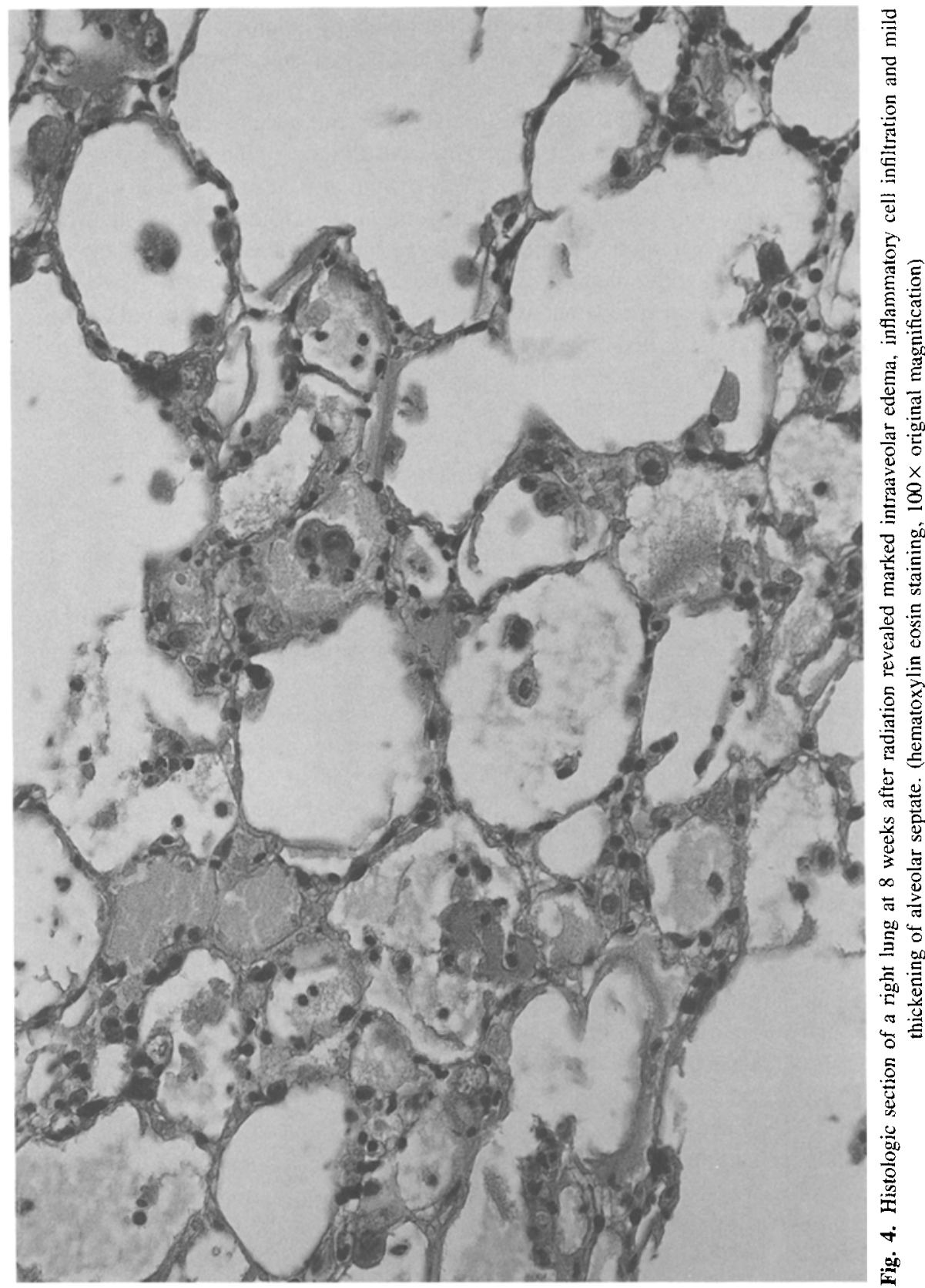


gen fibrosis replaced the earlier pneumonitis at $10-16$ weeks after 30 Gy thoracic irradiation (Figure 5). With 15 Gy irradiation, both inflammatory and fibrotic changes were much less pronounced, correlating with the lower inflammatory cell counts and TGF $\beta$ protein levels in BAL fluids.

Immunoreactive TGF $\beta$ was constitutively present in sham-irradiated or nonirradiated left lung localized at the connective tissue around bronchioles and vessels. At 4 weeks after irradiation, TGF $\beta$ immunoreactivity was also noted in the perivascular and peribronchiolar area but in somewhat patchy fashion. At later time points, immunoreactive TGF $\beta$ was mainly localized in thickened alveolar septa and within areas of fibroblastic proliferation (Figure 6). The irregular size and shape of type II pneumocytes in fibrotic lungs as compared to nonirradiated lungs were demonstrated by anti-surfactant staining (Figures $7 \mathrm{a}$ and $7 \mathrm{~b})$.

\section{DISCUSSION}

Rats receiving 30 Gy whole lung irradiation in preliminary experiments invariably died by 9 weeks after the radiation. Histologic sections of the lungs after death showed marked intraalveolar edema, inflammatory cell infiltration, and early fibrosis. In order to study the later phase of radiation fibrosis in the lung and to avoid any cardiac irradiation effects, we treated only the right hemithorax with $30 \mathrm{~Gy}$ irradiation for the BAL cytokine measurement and cell counts. However, the histologic changes in whole lung- and right lung-irradiated rats appeared similar during the initial 9 week-period.

The pathogenetic role of TGF $\beta$ has been studied by Phan et al and several other investigators in a model of bleomycin-induced fibrosis (14-20). Steadystate TGF $\beta$ mRNA expression is maximally elevated 1 week after bleomycin exposure, preceding the rise in gene expression for procollagens, fibronectin, and laminin in this model (21). In our thoracic irradiation model, the upregulation of TGF $\beta$ mRNA and protein expression also preceded histologically recognizable fibrosis, suggesting a pathogenetic role for TGF $\beta$ in radiation induced pulmonary fibrosis. A marked increase in TGF $\beta$ protein level in lung homogenates has been reported in the bleomycin-induced fibrosis model (22). Immunohistochemical staining using $\mathrm{CC}$ polyclonal antibody that detects secreted form of $\operatorname{TGF} \beta$ showed that $\operatorname{TGF} \beta$ was mainly localized to the site of fibrosis as previously reported by Limper et al. (23). Alveolar macrophages and bronchial epithelial cells in the present study did not show significant TGF $\beta$ staining in contrast to a previous report (24), probably because the CC antibody only detects the secreted form of TGF $\beta$. Immunoreactive $\mathrm{TGF} \beta$ in fibrotic areas was detected even after the TGF $\beta$ increase in BAL fluid subsided. Limper et al. 


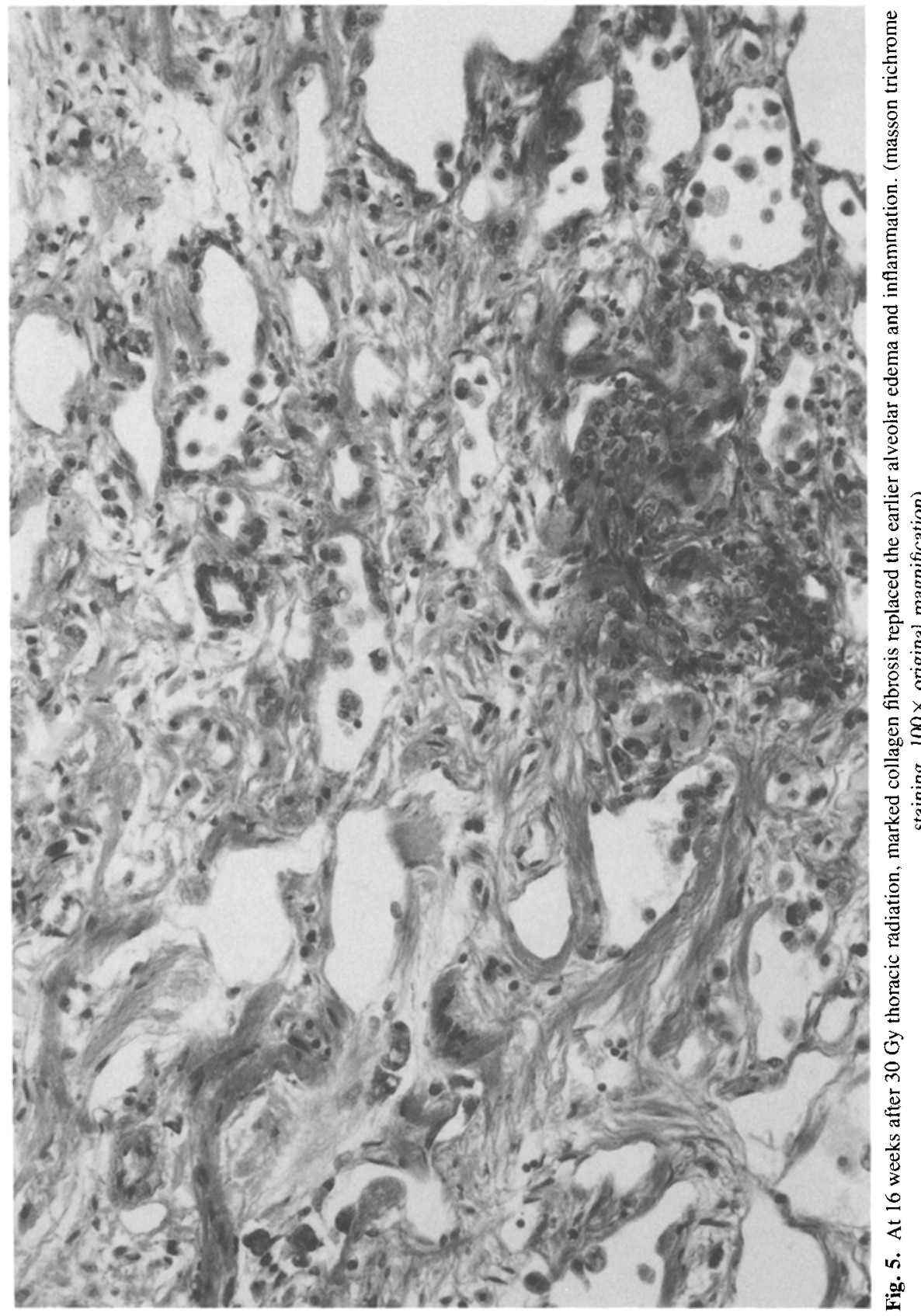




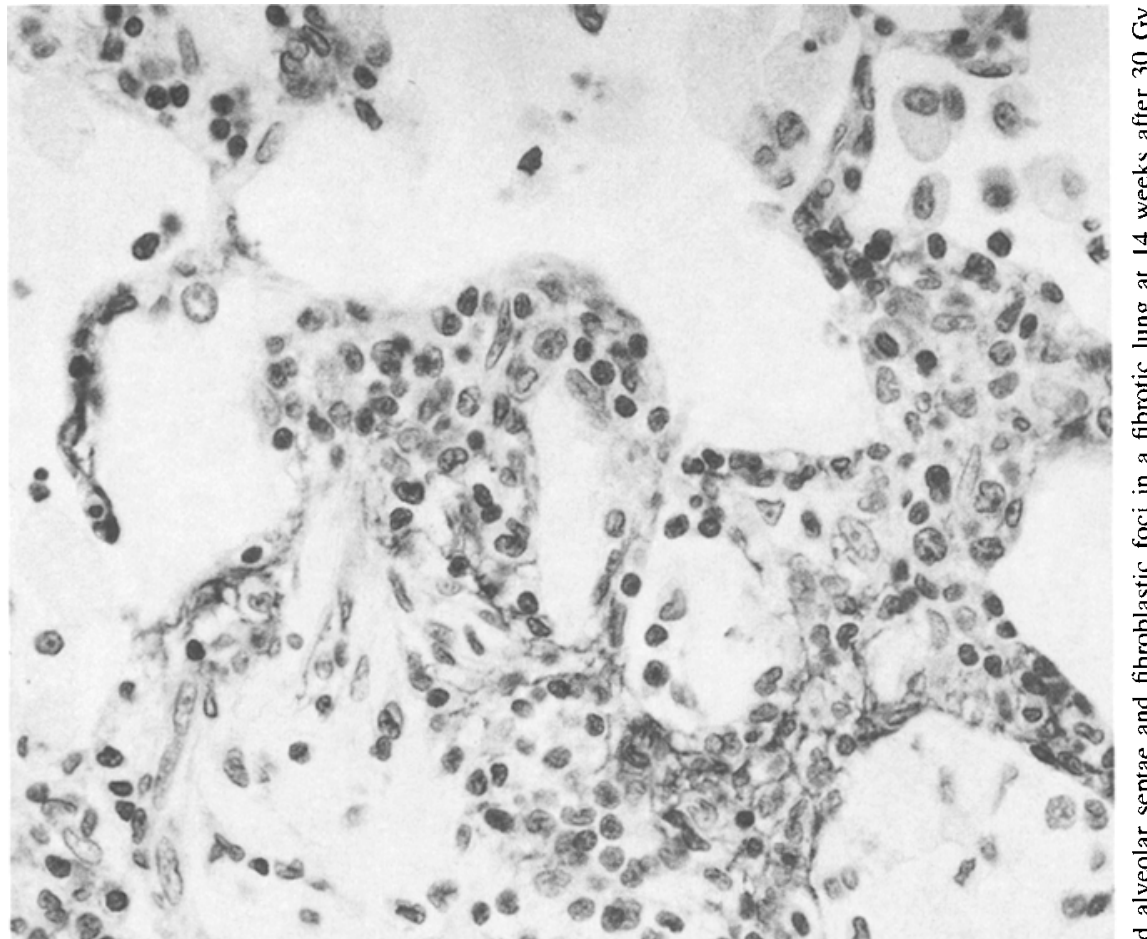

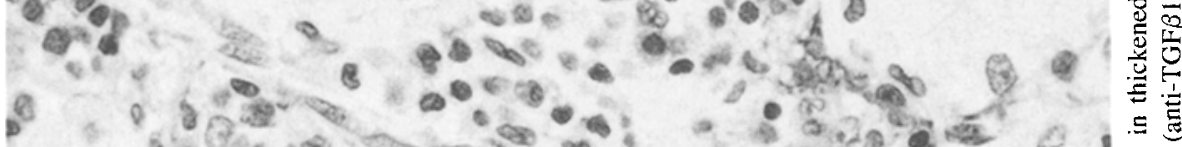

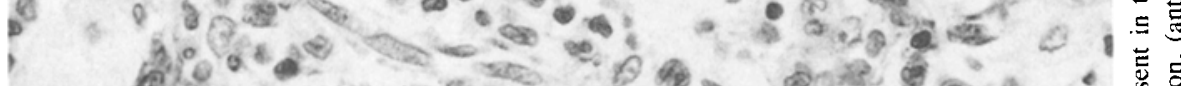





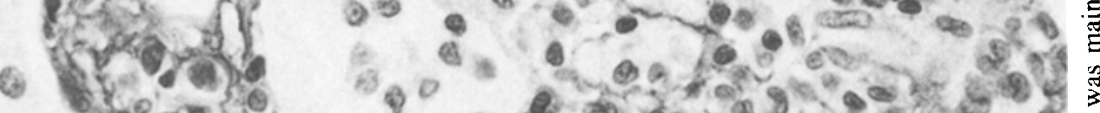

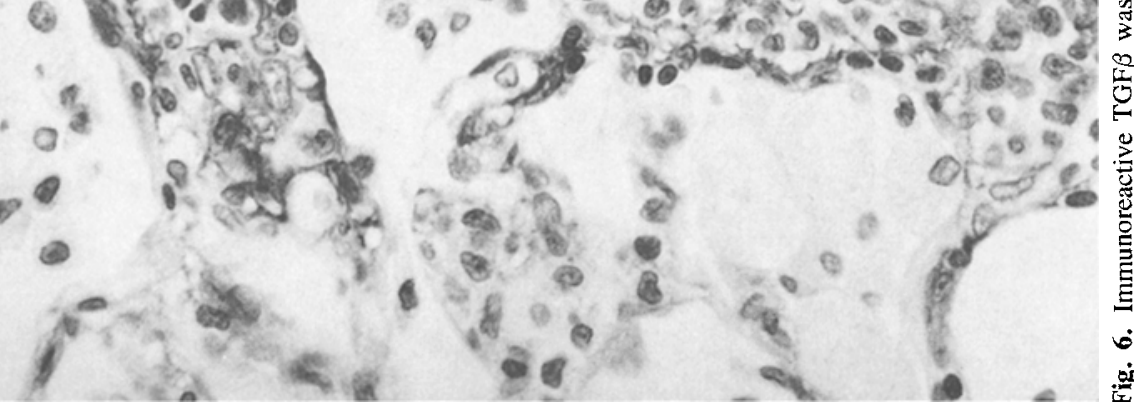




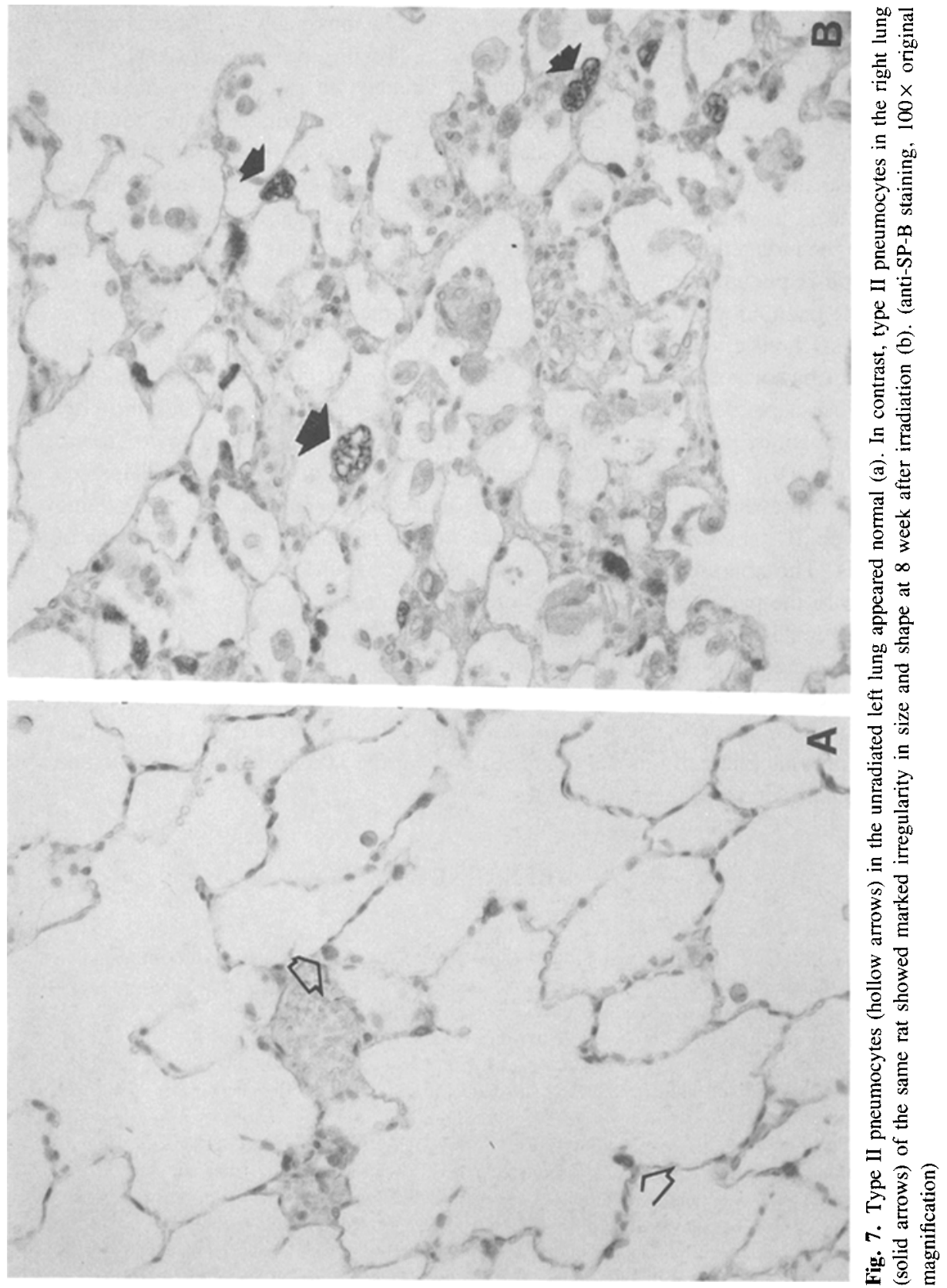


suggested that secreted TGF $\beta$ diffuses away from the producing cells and is concentrated in extracellular matrix of fibrotic lesions such as idiopathic pulmonary fibrosis and bronchiolitis obliterans organizing pneumonia (23).

Light microscopic and ultrastructural changes in radiation induced lung injury have been well studied in the past (25). A quantitative morphometric study at 12 to 26 weeks after unilateral 30 Gy thoracic irradiation showed a decrease in type I and II pneumocytes and capillary endothelial cells and an increase in interstitial cells and matrix as the morphologic basis for functional loss in the radiated lung (26). The lung cells most susceptible to radiation include the type II pneumocytes, endothelial cells, and alveolar macrophages $(1,24)$. Type II pneumocyte damage has been demonstrated by ultrastructural study as early as 1 hour after radiation and results in the immediate release of surfactant (1). Plasma surfactant apoprotein level has been shown to increase after radiation in a dose-dependent manner and has been proposed as a marker for the later development of pulmonary fibrosis (27). Pretreatment with keratinocyte growth factor (KGF), a potent type II pneumocyte growth factor in vivo (28), has been shown to prevent the bleomycin-induced lung fibrosis in rats (29), suggesting that type II pneumocytes are important in the regulation of development of fibrosis. The abnormality of type II pneumocytes found in our study might be related to the pathogenesis of radiation-induced fibrosis.

In conclusion, the early expression of $\mathrm{TGF} \beta$ in the course of radiationinduced lung injury is consistent with the current concept that release of cytokines such as TGF $\beta$ after radiation leads to the later development of fibrosis. A better understanding of the roles of individual cytokines in radiation lung injury could provide clinically useful means to prevent the late fibrosis by specific and early intervention of these molecules.

\section{REFERENCES}

1. RuBin, P., L. S. CoNSTINE, and D. F. NELSON, 1992. Late effects of cancer treatment: radiation and drug toxicity. In C. A. Perez, and L. W. Brady, editors. Principles and practices of radiation oncology, 2nd ed. J. B. Lippincott, New York. 131-134.

2. Hallahan, D. E., A. Haimovitz-Friedman, D. W. Kufe, Z. FuKs, and R. R. Weichsel BAUM. 1993. In The role of cytokines in radiation oncology. Important advances in oncology, V. T. DeVita, S. Hellman, and S. A. Rosenberg, editors. J. B. Lippincott, New York. pp. $71-80$

3. Witte, L., Z. Fuks, A. Haimovitz-Friedman, I. Vlodavsky, D. S. Goodman, and A. ELDOR. 1989. Effects of irradiation on the release of growth factors from cultured bovine, porcine, and human endothelial cells. Cancer Res. 49:5066-5072.

4. Rubin, P., J. Finkelstein, and D. Shapiro. 1992. Molecular biology mechanisms in the radiation induction of pulmonary injury syndromes. Interrelationship between the alveolar macrophages and the septal fibroblast. Int. J. Radiation Oncology Biol. Phys. 24:92-101. 
5. Rosiello, R. A., W. W. Merrill, D. Rockwell, D. Carter, J. A. D. Cooper, S. Care, and E. P. AmEnto. 1993. Radiation pneumonitis. Bronchoalveolar lavage assessment and modulation by a recombinant cytokine. Am. Rev. Respir. Dis. 148:1671-1676.

6. Barcellos-Hoff, M. H., R. Derynck, M. L. S. Tsang, and J. A. Weatherbee. 1994. Transforming growth factor beta activation in irradiation murine mammary gland. J. Clin. Invest. 93:892-899.

7. Anscher, M. S., T. Murase, D. M. Prescott, L. B. Marks, H. Reisenbichler, G. C. Bentel, D. Spencer, G. Sherouse, and R. L. Jirtle. 1994. Changes in plasma TGFbeta level during pulmonary radiotherapy as a predictor of the risk of developing radiation pneumonitis. Int. J. Radiation Oncology Biol. Phys. 30:671-676.

8. Finkelstein, J. N., C. J. Johnston, R. BagGs, and P. Rubin. 1994. Early alterations in extracellular matrix and transforming growth factor beta gene expression in mouse lung indicative of late radiation fibrosis. Int. J. Radiation Oncology Biol. Phys. 28:621-631.

9. Ulich, T. R., L. R. Watson, S. Yin, K. Guo, P. Wang, H. Thang, and J. del Castillo. 1991. The intratracheal administration of endotoxin and cytokines. I. Characterization of LPS induced IL-1 and TNF and mRNA expression and the LPS-, IL-1, and TNF-induced inflammatory infiltrate. Am. J. Pathol. 138:1485-1496.

10. Danielpour, D., K. Y. Kim, L. L. Dart, S. Watanabe, A. B. Roberts, and M. B. Sporn. 1989. Sandwich enzyme-linked immunosorbent assays (SELISAs) quantitate and distinguish two forms of transforming growth factor-beta (TGF $\beta 1$ and TGF- $\beta 2$ ) in complex biological fluids. Growth Factors 2:61-71.

11. Chomczynski, P., and N. SACCHI. 1987. Single-step method of RNA isolation by acid guanidium thiocyanate-phenol-chloroform extraction. Anal. Biochem. 162:156-159.

12. Qian, S. W., P. Kondaiah, A. B. Roberts, and M. B. Sporn. 1990. cDNA cloning by PCR of rat transforming growth factor beta-1. Nucleic Acids Res. 18:3059.

13. Hsu, S. M., L. RaIne, and H. FAnger. 1981. The use of antiavidin antibody and anti-biotinperoxidase complex in immunoperoxidase techniques. Am. J. Clin. Pathol. 75:816-821.

14. Phan, S. H., and S. L. Kunkel. 1992. Lung cytokine production in bleomycin-induced pulmonary fibrosis. Exp. Lung Research 18:29-43.

15. Kelley, J. 1993. Transforming growth factor beta. In Cytokines of the Lung, 1st ed., J. Kelley, editor. Marcel Dekker, New York. 101-137.

16. RaGHOW, R., P. IRISH, and A. H. KANG. 1989. Coordinate regulation of transforming growth factor beta gene expression and cell proliferation in hamster lungs undergoing bleomycininduced pulmonary fibrosis. J. Clin. Invest. 84:1836-1842.

17. Breen, E., S. Shull, S. Burne, M. Absher, J. Kelley, S. Phan, and K. R. Cutroneo. 1992. Bleomycin regulation of transforming growth factor-beta mRNA in rat lung fibroblasts. Am. J. Res. Cell Mol. Biol. 6:146-152.

18. Khalil, N., R. N. O’Connor, K. C. Flanders, W. Shing, and C. I. Whitman. 1994. Regulation of type II alveolar epithelial cell proliferation by TGF-beta during bleomycin-induced lung injury in rats. Am. J. Physiol. 267:L498-507.

19. Giri, S. N., D. M. Hyde, and M. A. Hollinger. 1993. Effect of antibody to transforming growth factor beta on bleomycin induced accumulation of lung collagen in mice. Thorax 8:959966.

20. Westergren-Thprsson, G., J. Hernnas, B. Sarnstrand, A. Oldberg, D. Heinegard, and A. MalmStrom. 1993. Altered expression of small proteoglycans, collagen, and transforming growth factor-beta 1 in developing bleomycin-induced pulmonary fibrosis in rats. J. Clin. Invest. 92:632-637.

21. HoYt, D. G., and J. S. LAzo. 1990. Bleomycin and cyclophosphamide increase pulmonary type IV collagen mRNA in mice. Am. J. Physiol. 259:L47-L52. 
22. Khalit, N., O. Bereznay, M. Sporn, and A. H. Greenberg. 1989. Macrophage production of transforming growth factor beta and fibroblast collagen synthesis in chronic pulmonary fibrosis. J. Exp. Med. 170:727-737.

23. Limper, A. H., T. J. Broekelmann, T. V. Colby, G. Malizia, and J. A. McDonald. 1991. Analysis of local mRNA expression of extracellular matrix proteins and growth factors using in situ hybridization fibroproliferative lung disorders. Chest 99:55S-56S.

24. Khalil, N., R. N. O'Connor, H. W. Unruh, P. W. Warren, K. C. Flanders, A. Kemp, O. H. Bereznay, and A. H. Greenberg. 1991. Increased production and immunohistochemical localization of transforming growth factor beta in idiopathic pulmonary fibrosis. Am. J. Resp. Cell Mol. Biol. 5:155-162.

25. McDonald, S., P. Rubin, and P. Maasilta. 1989. Response of normal lung to irradiation. Tolerance doses/tolerance volumes in pulmonary radiation syndromes. In Radiation tolerance of normal tissues, J. M. Vaeth, and J. L. Meyer, editors. Karger, Basel. 255-276.

26. Veragara, J. A., U. Raymond, and L. A. Thet. 1986. Changes in lung morphology and cell number in radiation pneumonitis and fibrosis: A quantitative ultrastructural study. Int. J. Radiation Oncol. Biol. Phys. 13:723-732.

27. Rubin, P., S. McDonald, P. Maasilta, J. N. Finkelstein, D. L. Shapiro, D. Penney, and P. K. GREGORY. 1989. Serum markers for production of pulmonary radiation syndromes. Part I: Surfactant apoprotein. Int. J. Radiation Oncol. Biol. Phys. 17:553-558.

28. Ulich, T. R., E. S. Yi, K. Longmuir, S. Yin, R. Blitz, C. Morris, R. M. Housley, and G. F. PIERCE. 1994. Keratinocyte growth factor is a growth factor for type II pneumocytes in vivo. J. Clin. Invest. 93:1298-1306.

29. Deterding, R. R., T. Yano, A. M. Havill, C. R. Jacoby, J. M. Shannon, W. S. Simonet, and R. J. MASON. 1995. Keratinocyte growth factor prevents bleomycin lung injury in rats. Am. J. Resp. Crit. Care Med. 151:A198. 